\title{
Optimization and Acceptability Evaluation of Shapporah Biscuits Formulated by Different Ingredients: Using Response Surface Methodology (RSM)
}

\author{
Waleed AL-Ansi ${ }^{1,2,4}$, Amer Ali Mahdi ${ }^{1,2,4}$, Yan Li ${ }^{1,2,3}$, Haifeng Qian ${ }^{1,2,3}$, Li Wang ${ }^{1,2,3, *}$ \\ ${ }^{1}$ State Key Laboratory of Food Science and Technology, Jiangnan University, Wuxi 214122, China \\ ${ }^{2}$ School of Food Science and Technology, Jiangnan University, Wuxi 214122, China \\ ${ }^{3}$ National Engineering Research Center for Functional Food, Jiangnan University, Wuxi 214122, China \\ ${ }^{4}$ Department of Food Science and Technology, Faculty of Agriculture, Sana'a University, Sana'a, Yemen \\ *Corresponding author:w10519@163.com
}

\begin{abstract}
The present study aimed to optimize the replacement levels of sugar and different types of flour to develop a traditional biscuit. The study was carried out using mixture response surface methodology (RSM) as the optimization technique. The biscuits optimum formula was designed using the following mixing ratio: lentil flour: millet flour (22.53 g: $11.47 \mathrm{~g}$ ), whole wheat flour: wheat flour (42.04 g: $23.96 \mathrm{~g}$ ) and sugar (35.61\%), based on the biscuits sensory evaluations. Physical properties of composite flour biscuits (COMFB) showed a higher thickness but lower in term of spread ratio, diameter and weight compared to the mixture of whole wheat and wheat flours biscuit (MIXFB) and wheat flour biscuits (WFB). COMFB was harder and color difference $(\triangle \mathrm{E})$ was higher and significantly darker surface than MIXFB and WFB. Sensory evaluation of COMFB showed higher consumers acceptance compare to MIXFB which indicates that the acceptance of the whole wheat flour based biscuits can be improved by using composite flour such as this formula. Optimization suggested composite flour biscuits (COMFB) as the best formula. This sample received good scores for the sensory attributes.
\end{abstract}

Keywords: sensory evaluation, response surface methodology, lentil flour, millet flour, traditional biscuits

Cite This Article: Waleed AL-Ansi, Amer Ali Mahdi, Yan Li, Haifeng Qian, and Li Wang, "Optimization and Acceptability Evaluation of Shapporah Biscuits Formulated by Different Ingredients: Using Response Surface Methodology (RSM)." Journal of Food and Nutrition Research, vol. 6, no. 3 (2018): 192-199. doi: 10.12691/jfnr-6-3-9.

\section{Introduction}

Biscuits, also known as cookies in America, are widely consumed all over the world by adults and children alike. Composite flour biscuits are traditional biscuits in Yemen such as Shapporah, it consumed by a large segment of the population in celebrations and events as a snack or kind of desserts. It has high nutritional value and distinct taste [1]. The biscuits are produced in homes and there are so far no studies for the development or application of these types of cookie in food industries. The basic ingredients of Shapporah biscuits are whole wheat flour (WWF), lentil Fluor (LF), wheat Flour (WF), millet flour (MF), ghee or butter and sugar with other additives in some regions to enhance the taste and extend the shelf life. Most baked products especially biscuits are produced from wheat flour. Wheat does not grow well in the tropics and has to be imported by countries in these regions. Incessant increases in the cost of wheat have in turn led to constant increases in the price of these products. This had led to the need to develop alternatives to the use of wheat flour in the production of baked goods. Efforts have been made to promote the use of composite flour in which flours from locally grown crops and high protein seeds totally or partially replace wheat flour for use in baked goods thereby decreasing the demand for imported wheat and producing protein enriched products [2]. In selecting the components to be used in composite flour blends, the materials should preferably be readily available, culturally acceptable and provide increased nutritional potential.

Traditional foods are essential components of the nutritional patterns of several populations, including those of contemporary developed societies. Customer demand for traditional meals is high in many western countries [3]. Food usage patterns were shaped, until recently, by durable and regional cooperation among a number of socioeconomic actors. This cooperation has left an imprint over time on current group and individual food preferences [4]. Within the last few decades, both food companies and public authorities have demonstrated an ever-growing interest in traditional foods. The traditional food sector, as an additional sector of the meals industry, faces the need to innovate and develop its product continuously, to be able to maintain or increase market share and profitability [5].

Wheat grain (Triticum aestivum L.) is among the major resources of food for individuals in 43 various countries, accounting for $35 \%$ of the total world human population that frequently consume wheat-based food [6]. In 
conditions of usage, it ranks second after rice as the primary human meals crop [7]. The greater protein content in wheat in comparison to various other cereals such as maize and rice also helps it be a leading way of obtaining cereal protein in human being nourishment [8]. However, its proteins contain low amounts of essential amino acids such as for example threonine and lysine [9].

The supplementation of wheat flour with legume flours is a highly effective means of enhancing the dietary quality of cereal-based foods. The legumes' amino acid composition is certainly complementary to the main composition of cereals [10].

Lentils (Lens culinaris Medik.) are consumed worldwide commonly, in the Mediterranean area particularly. They are known to induce short-term satiety and a minimal glycaemic response and also to be of assistance in body excess weight maintenance, because of the existence of $\beta$-glucans [11]. Lentils also contain phytochemicals such flavanols, phenolic acids, flavonols, condensed tannins, saponins and phytic acid [12], and antioxidant characteristics exist as well [13]. Lentils are a great food source abundant with protein, fiber, vitamins and minerals. Lentils are also lower in unwanted fat [14].

Pearl millet [Pennisetum glaucum (L) Leake] is an important cereal, contributing to the calorie and protein requirements of people in the semi-arid tropics (SAT). It is grown mostly in regions of low rainfall and is capable of withstanding adverse agro-climatic conditions. More than $80 \%$ of the production is used for human consumption, particularly in the SAT region of Africa and Asia. Several food preparations are made from pearl millet in Africa and India [15]. In Yemen, pearl millet has remained as a staple food in the form of gruels for the poor.

Nutritionally, pearl millet is usually superior to wheat, sorghum and maize when it comes to minerals, protein, energy density, fat and vitamins [16].

Biscuits are the most popular bakery varieties consumed almost by all categories of society. It has good dietary quality, and availability in various varieties and affordable prices [17]. Most of the bakery items are utilized as a resource for integrating the various nutritionally wealthy ingredients for their diversity. Several health items have finally become available [18].

Response surface methodology (RSM) is a statistical tool which is magnificently used in the development and optimization of food products [19] Also, it can be used to systematically determine the effects of multiple variables in a mixture on quality attributes while minimizing the number of experiments that must be conducted [20]. However, it is a collection of mathematical and statistical techniques beneficial for evaluating and optimizing the response of multivariate systems [21]. RSM model will reduce the number of trials and provide multiple regression approach. The optimized ingredients level accomplished after the numerical and graphical optimization serves better for maximum score such as colour, flavour and taste Bafna, (2013).

This work therefore seeks to use RSM coupled Box-Behnken design (BBD) as the optimization technique, to produce Shapporah biscuits from blends of LF, MF and WF which have consumer's acceptance similar to or even better than that obtained for whole wheat biscuits.

\section{Materials and Methods}

\subsection{Materials}

Whole wheat flour (WWF) and wheat flour (WF) were supplied from COFCO Xiangxue flour Co., Ltd. China, millet was purchased from (Liaoning Dongya Agricultural Development Co., Ltd China. and lentil was purchased from (Memiş Food Industry and Trade Co. Ltd -Turkey).

\subsection{Experimental Design and Single-factor Experimental}

Single-factor experiments were firstly done to optimize the influences of different levels of replacement procedure of WWF, WF, millet flour (MF), lentil flour (LF), and sugar on the overall acceptance and to reduce the total experimental work, the outcomes were presented in Table 1. Variables that were not studied were held constant. In the LF: MF trials, the constant values for WWF to WF ratio and sugar concentration were 46.2:19.8 g/g and 30\% respectively. In the WWF: WF trials, the constant values of LF to MF ratio and sugar concentration were $25: 9 \mathrm{~g} / \mathrm{g}$ and $30 \%$. In the LF: MF trials, the constant values for LF to $\mathrm{MF}$ ratio and $\mathrm{WWF}$ to $\mathrm{WF}$ ratio was as resulted in above experiments 25:9 g/g and 46.2:19.8g/g respectively.

Table 1. Single-factor experiments

\begin{tabular}{|c|c|c|c|c|c|}
\hline LF & $\begin{array}{c}\text { Overall } \\
\text { acceptance }\end{array}$ & WWF & $\begin{array}{c}\text { Overall } \\
\text { acceptance }\end{array}$ & Sugar & $\begin{array}{c}\text { Overall } \\
\text { acceptance }\end{array}$ \\
\hline 14 & 6.98 & 33.6 & 6.82 & 20 & 6.49 \\
\hline 17 & 6.98 & 39.6 & 7.16 & 25 & 6.56 \\
\hline 20 & 6.59 & 46.2 & 7.19 & 30 & 7.19 \\
\hline 25 & 7.19 & 52.8 & 6.68 & 35 & 7.20 \\
\hline 30 & 7.06 & 95.4 & 7.09 & 40 & 6.87 \\
\hline
\end{tabular}

\subsection{Orthogonal test design (BBD)}

Predicated on the single-factor experimental outcomes in Table 1, degrees of major influential factors are confirmed in Table 2. This work strives to optimize the effect of replacement levels of LF/MF $\left(\mathrm{X}_{1}\right)$, WWF/WF $\left(\mathrm{X}_{2}\right)$ and the sugar concentration $\left(\mathrm{X}_{3}\right)$ for a maximum overall acceptance $\left(\mathrm{Y}_{1}\right)$. Table 2 demonstrated the independent variables, the response and levels of BBD matrix for both of the predicted and actual values. The mathematical relationship between the independent variables $\left(\mathrm{X}_{1}, \mathrm{X}_{2}\right.$ and $\left.\mathrm{X}_{3}\right)$ and the response $(\mathrm{Y})$ could be proceed by the quadratic polynomial model in terms of coded levels, as demonstrated in Eq.1 [23].

$$
y=\beta_{0}+\sum_{i=1}^{k} \beta_{i} x_{i}-\sum_{i=1}^{k} \beta_{i i} x_{i i}^{2}+\sum_{1 \leq i \leq j}^{k} \beta i_{j} x_{i} x_{i j}
$$

Where y represents the response, xi, xii and xij will be the coded independent variables affecting the response, $\beta \mathrm{i}$ represents the coefficients of the linear parameters, $\beta 0$ is the regression coefficients for intercept (constant), $\beta \mathrm{ii}$ is the coefficients of the quadratic parameter, $\beta \mathrm{ij}$ represents the coefficients of the interaction parameters, $\mathrm{k}$ is the number of variables, $\varepsilon$ is the residual associated with the 
experiments. To assess the adequacy of the predictive models, the consumer's acceptance of the obtained formula was carried out by 60 judges in the between 20-50 years old comprised of consumers and college students under the innovative optimal conditions.

Table 2. Box-Behnken design (BBD), predicted and actual values of overall acceptance

\begin{tabular}{cccccc}
\hline & & & \multicolumn{3}{c}{ Response } \\
Run & $\mathrm{X}_{1}$ & $\mathrm{X}_{2}$ & $\mathrm{X}_{3}$ & Acceptance & Predicted \\
\hline 1 & 20.0 & 46.2 & 30.0 & 6.11 & 6.11 \\
2 & 30.0 & 46.2 & 40.0 & 5.88 & 5.88 \\
$3^{\mathrm{a}}$ & 25.0 & 46.2 & 35.0 & 7.21 & 7.21 \\
4 & 30.0 & 52.8 & 35.0 & 6.53 & 6.54 \\
$5^{\mathrm{a}}$ & 25.0 & 46.2 & 35.0 & 7.23 & 7.21 \\
6 & 25.0 & 52.8 & 40.0 & 6.29 & 6.28 \\
7 & 25.0 & 39.6 & 40.0 & 6.59 & 6.59 \\
8 & 20.0 & 52.8 & 35.0 & 6.56 & 6.56 \\
9 & 25.0 & 39.6 & 30.0 & 6.39 & 6.40 \\
10 & 20.0 & 46.2 & 40.0 & 6.6 & 6.61 \\
$11^{\mathrm{a}}$ & 25.0 & 46.2 & 35.0 & 7.2 & 7.21 \\
$12^{\mathrm{a}}$ & 25.0 & 46.2 & 35.0 & 7.21 & 7.21 \\
13 & 30.0 & 46.2 & 30.0 & 6.09 & 6.08 \\
14 & 25.0 & 52.8 & 30.0 & 6.16 & 6.16 \\
15 & 30.0 & 39.6 & 35.0 & 6.46 & 6.46 \\
16 & 20.0 & 39.6 & 35.0 & 7.19 & 7.18 \\
$17^{\mathrm{a}}$ & 25.0 & 46.2 & 35.0 & 7.21 & 7.21 \\
\hline
\end{tabular}

$\mathrm{X}_{1}$, Factor $1 \mathrm{LF}: \mathrm{MF}(\mathrm{g})$; $\mathrm{X}_{2}$, Factor $2 \mathrm{WWF}: \mathrm{WF}(\mathrm{g})$; $\mathrm{X}_{3}$, Factor 3 sugar(g); ${ }^{\mathrm{a}}$ Center points.

\subsection{Biscuit Formula and Preparation}

Flour formulas used were according to a traditional cookie formula in Yemen and made using the method described by [24] with some modifications: The basic recipe for the biscuit dough (based on $100 \mathrm{~g}$ of flour) was sugar, 18-20 g water, $25 \mathrm{~g}$ unsalted butter (WESTOROWestland Milk Products-Hokitika-New Zealand), 1 g salt, $0.9 \mathrm{~g}$ baking soda, $1 \mathrm{~g}$ ammonium bicarbonate and $1 \mathrm{~g}$ sodium bicarbonate.

WF in the control recipe was replaced with WWF in a ratio of (30:70) respectively, to obtain the mixture flour biscuits (MIXFB). The second group was wheat flout biscuits (WFB), and the third group was the composite flour biscuits (COMFB), the flour formulas were according to the single factor and optimum formula of RSM works. The WFB and MIXFB were made as controls. Millet and lentil grains were milled in the laboratory. Flours and sugar passed through $(0.8 \mathrm{~mm}$ openings) sieve. The flours were mixed with the butter with a low speed for $2 \mathrm{~min}$ by a KENWOOD mixer Kenwood Limited, New Lane, Havant, Hampshire PO9 2NH-U.K. with a flat beater. Three formulations of biscuits were prepared maintaining the same recipe except for the type and content of flour added. Sugar, ammonium bicarbonate, baking soda, salt and sodium bicarbonate were added to the flours after dissolving in water and obtaining a homogeneous cream, then mixed for $3 \mathrm{~min}$ to acquire a homogeneous dough. Using a rolling pin of 2 $\mathrm{mm}$ thickness, dough was sheeted and biscuits were created by a cutter of $5 \mathrm{~cm}$ diameter. Biscuits were baked at $190^{\circ} \mathrm{C}$ for $10 \mathrm{~min}$, cooled to room temperature for $30 \mathrm{~min}$, and stored in airtight plastic containers at room conditions.

\subsection{Physical Characteristics}

The physical properties measurements of the biscuits were weight, thickness, diameter, and spread factor. Weight of the biscuits was determined utilizing an analytical electronic precision balance $0.001 \mathrm{~g}$. It has been adopted the following method reported by [25] for diameter measurement of the biscuits: four biscuits randomly chosen were put edge-to-edge and the total diameter was measured with a vernier caliper, then all biscuits were revolved by $90^{\circ}$ and the new measurement was taken, the final biscuit diameter was calculated as mean of the measurements split by four. Biscuits thickness was estimated by stacking six biscuits one on the top the other by using of vernier caliper and restacking four times, the mean of the readings was taken. The spread ratio of the biscuits was calculated using the formula: dividing the average value of the diameter by the thickness of biscuits [26].

\subsection{Determination of Colour}

The measurements were done utilizing UltraScan Pro1166 (Hunterlab, USA). Three independent measurements of $\left[L^{*}\right.$ (lightness), $a^{*}$ (redness) and $b^{*}$ (yellowness)] parameters were carried out in different parts of the biscuit surface. The colour difference $\Delta E *$ between two samples is described by the Eq. 2:

$$
\Delta E^{*}=\sqrt{\left(\Delta L^{*}\right)^{2}+\left(\Delta a^{*}\right)^{2}+\left(\Delta b^{*}\right)^{2}}
$$

Where $\Delta L *, \Delta b *$ and $\Delta a *$ are the variation among the two samples in $L *, b *$ and $a *$ respectively. The observation of the colour variation $\Delta E *$ varies based on the colour absorbed and the sensitivity of the human eye $[27,28]$.

\subsection{Texture Analysis (Three-Point Break Test)}

The snap power as a maximum force at bend deformation to fracture was evaluated utilizing a 3-point brake test (TA-XT plus, Stable Micro Systems, UK) to analyze the biscuit fracture strength. The length between the two beams was $40 \mathrm{~mm}$. Another congruent beam was brought down from above at a pre-test speed of $10.0 \mathrm{~mm} / \mathrm{s}$, post-test speed $10.0 \mathrm{~mm} / \mathrm{s}$, test speed $1.0 \mathrm{~mm} / \mathrm{s}, 5 \mathrm{~mm}$ distance to touch the biscuit. The downward movement continued until the biscuits snapped. The peak force was reported as the force of the fracture [26].

\subsection{Scanning Electron Microscopy}

The investigation of the microstructure for each type of the biscuit was carried out utilizing the scanning electron microscopy (SEM). The samples were mounted on specific sputtered and stub a conductive coating of gold. 
Samples were imaged utilizing a Hitachi HighTechnologies Corp., SEMSU 1510 (Tokyo, Japan) under high vacuum circumstances, operating at an accelerating beam voltage at $5.00 \mathrm{kV}$ and a working distance of 8.1$8.4 \mathrm{~mm}$. The upper surface and cross section of the samples for every individual biscuit type were exposed at several different magnifications [29].

\subsection{Sensory Evaluation}

Evaluation of the biscuits was carried out $48 \mathrm{~h}$ after the biscuits were produced. A total of 60 panelists between 20-50 years old comprised of college students (mentioned the college, Univ., Country) and customers. Criteria for selection of panelists were that panelists were regular consumers of biscuits and were not allergic to any food. Panelists were instructed to evaluate appearance, flavour, color, sweetness, mouth feel, hardness and overall acceptability of the biscuits. A 9-point hedonic scale was used with $1=$ dislike extremely, $5=$ neither like nor dislike and $9=$ like extremely $[30,31]$.

Samples were presented in a random sequence to panelists. All of the treatments including the control were randomly presented to each panelist. The evaluation was concluded in one session. The panelists were instructed to rinse their mouths with water after every sample and not to make comments during evaluation to prevent influencing other panelists. They were also asked to comment freely on samples on the questionnaires given to them.

\subsection{Statistical analysis}

Analysis of variance (ANOVA) was carried out on the data obtained followed by Duncan's Multiple Range test (SPSS v. 20.0 for windows (SPSS Inc., Illinois, USA) to determine difference in the means. A $p$ value below 0.05 was considered as significant. Regression analysis was performed on the sensory quality characteristics of the biscuits using Design-Expert ${ }^{\circledR}$ version 10.0.0 (Stat-Ease, Inc., USA). Model significance $(\mathrm{p}<0.05)$, lack of fit and adjusted coefficient of determination $\left(\mathrm{R}^{2} \mathrm{adj}\right)$, which indicate the model fitness were determined from the analysis.

\section{Results and Discussions}

\subsection{Optimization of the Overall Acceptability}

The overall acceptability utilizing a sensory evaluation of COMFB was implemented by 60 judges. The consumer's acceptance was performed in 17 runs using RSM to investigate the effect of different variables which included: LF: MF $\left(\mathrm{X}_{1}\right)$, WWF: WF $\left(\mathrm{X}_{2}\right)$ and sugar $\left(\mathrm{X}_{3}\right)$ on the response. The response was the overall acceptability.

\subsection{Fitting the Response Surface Models}

The RSM was done to evaluate the effects of composite flours on the overall acceptance and optimized conditions for the response. BBD was applied with three numeric factors on three amounts [32]. This design consisted of 12 randomized runs with five replicates at the central point to reduce the mistakes. The factors $\mathrm{X}_{1}, \mathrm{X}_{2}$ and $\mathrm{X}_{3}$ were used to optimize the experiment conducted by a $3^{3}$ full factorial BBD. Table 2 abridged the experimental design, predicted values and actual response value of the biscuits overall acceptance (Y). Multiple regression analysis was utilized for the experimental data to gain access to the second level polynomial equations to attain the maximum overall acceptance. The ultimate equations of coded independent factors as follows:

$$
\begin{aligned}
& \mathrm{Y}(\text { Acceptance }) \\
& =7.21-0.19 \mathrm{X} 1-0.14 \mathrm{X} 2+0.076 \mathrm{X} 3 \\
& +0.17 \mathrm{X} 1 \mathrm{X} 2-0.17 \mathrm{X} 1 \mathrm{X} 3-0.018 \mathrm{X} 2 \mathrm{X} 3 \\
& -0.36 \mathrm{X} 12-0.17 \mathrm{X} 22-0.68 \mathrm{X} 32 .
\end{aligned}
$$

The equation when it comes to coded factors can be used to create predictions about the response for given levels of each factor. By default, the low degrees of the factors are coded as -1 and the high degrees of the factors are coded as +1 . The coded equation is beneficial for defining the relative influence of the factors compared to the factor coefficients. Outcomes of evaluation variance (ANOVA) are shown in Table 3. The regression coefficients of the mathematical models describe the biscuits overall acceptance and also summarize the importance of the regression coefficients and the adequacy and fitting quality of the models in Eq. 3. The overlapping that happened between the LF:MF $\left(\mathrm{X}_{1}\right)$ and sugar $\left(\mathrm{X}_{3}\right)$ Figure 1_b, had a positive effect on improving the overall acceptance and was higher than in the case of overlapping which happened between the LF:MF $\left(\mathrm{X}_{1}\right)$ and the WWF:WF $\left(\mathrm{X}_{2}\right)$ Figure 1_a. At the same time, the overlapping that happened between the WWF: WF $\left(\mathrm{X}_{2}\right)$ and the sugar $\left(\mathrm{X}_{3}\right)$ had a positive response Figure 1_c. The optimum values of overall acceptance have been obtained at the level of sugar $35 \mathrm{~g}$. A positive relation started with the increase in overall acceptance until the optimum values were reached and then decreased in an inverse relation with $\mathrm{X} 1, \mathrm{X} 2$ and $\mathrm{X} 3$, and this is what can be observed through the concave smooth curves in Figure 1.

Table 3. Analysis of variance (ANOVA) for the overall acceptance of the biscuits

\begin{tabular}{ccccccc}
\hline Source & $\begin{array}{c}\text { Sum of } \\
\text { Squares }\end{array}$ & df & $\begin{array}{c}\text { Mean } \\
\text { Square }\end{array}$ & $\begin{array}{c}\text { F } \\
\text { Value }\end{array}$ & $\begin{array}{c}\text { p-value } \\
\text { Prob }>\text { F }\end{array}$ & \\
\hline Model & 3.57 & 9 & 0.40 & 2906.93 & $<0.0001$ & s. \\
A & 0.28 & 1 & 0.28 & 2061.52 & $<0.0001$ & \\
B & 0.15 & 1 & 0.15 & 1088.57 & $<0.0001$ & \\
C & 0.047 & 1 & 0.047 & 340.93 & $<0.0001$ & \\
AB & 0.12 & 1 & 0.12 & 897.91 & $<0.0001$ & \\
AC & 0.12 & 1 & 0.12 & 897.91 & $<0.0001$ & \\
BC & 0.001225 & 1 & 0.00123 & 8.98 & 0.0200 & \\
A $^{2}$ & 0.54 & 1 & 0.54 & 3938.91 & $<0.0001$ & \\
B & 0.12 & 1 & 0.12 & 889.30 & $<0.0001$ & \\
C & 1.97 & 1 & 1.97 & 14470.89 & $<0.0001$ & \\
Residual & 0.000955 & 7 & 0.00123 & & & \\
Lack of Fit & 0.000475 & 3 & 0.00016 & 1.32 & 0.3848 & ns \\
Pure Error & 0.00048 & 4 & 0.00012 & & & \\
Cor Total & 3.57 & 16 & & & & \\
\hline
\end{tabular}

A, LF: MF; B, WWF: WF; C, sugar; s, significant; ns, not significant. 

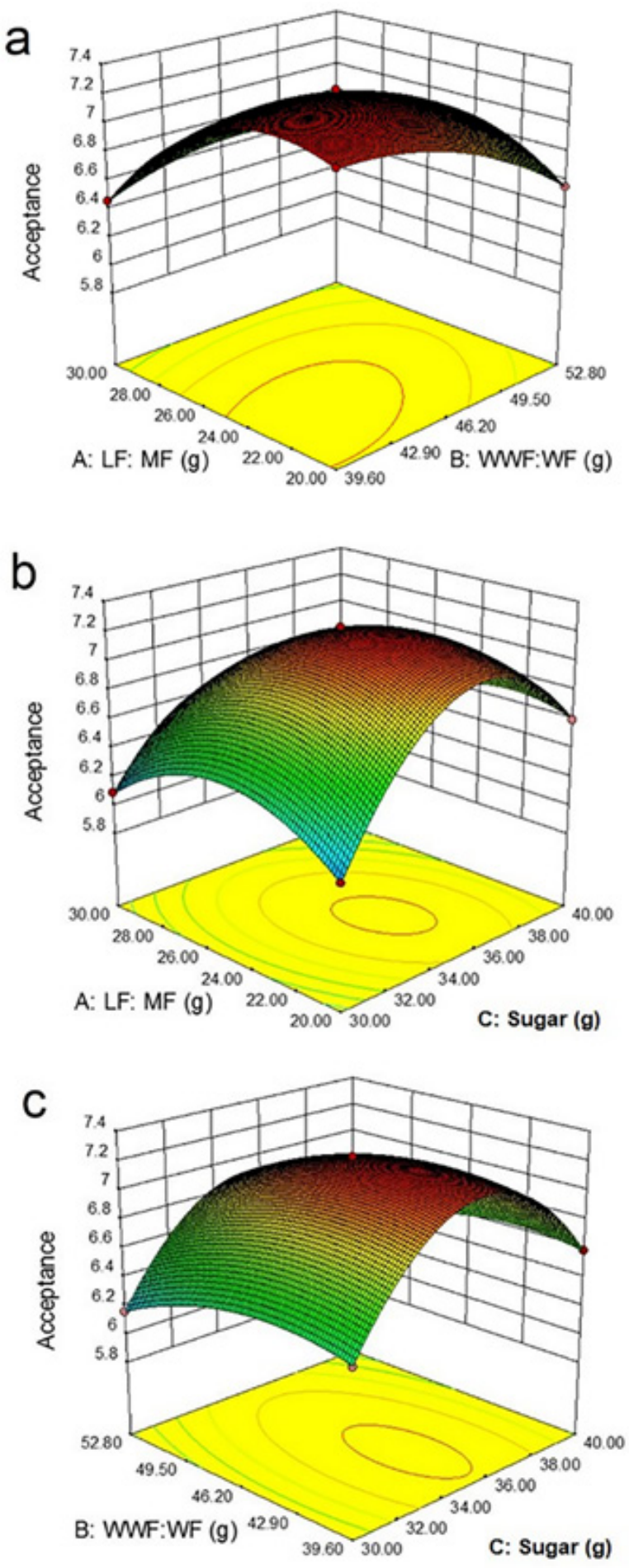

Figure 1. Three-dimensional response surface plots representing interaction effects: (a) LF: MF with WWF: WF, (b) LF: MF with Sugar and (c) WWF: WF with Sugar.

\subsection{Verification and Validation of Predictive Model}

To judge the adequacy of the model Eq. 3 the biscuits overall acceptability were evaluated as explained earlier. Under the innovative optimum conditions which included LF: MF (22.53 g: $11.47 \mathrm{~g})$, WWF: WF (42.04 g: $23.96 \mathrm{~g}$ ) and sugar $(35.61 \%)$. The predicted optimum acceptance was 7.30 and the mean result of the overall acceptance was 7.31 in a nine hedonic test. No significant difference was found between the predicted and experimental outcomes. Thus, these models can be beneficial to optimize the ingredients for a composite flour biscuit with maximum acceptance.

\subsection{Biscuits physical properties}

The results of the physical properties of the biscuits are summarized in Table 4. The MIXFB diameter was significantly $(\mathrm{p}<0.05)$ higher than COMFB. The thickness of COMFB was higher $(0.85 \mathrm{~mm})$ as compared to MIXFB and WFB which were $(0.80 \mathrm{~mm})$ and $(0.81 \mathrm{~mm})$ respectively. The thickness increased with the incorporation of LF, MF and WWF to WF. Similar results were observed by [33], they reported that cookies with soy flour added were thicker and smaller in diameter compared to wheat cookies due to the extreme water absorptive properties of soy flour. MIXFB had a higher weight as compared to WFB, the lowest weight was in COMFB. The higher weight of MIXFB biscuits may be due to the ability of WWF to retain more oil during the baking process.

Table 4. Physical properties and sensory evaluation of the biscuits

\begin{tabular}{lccc}
\hline & COMFB & MIXFB & WFB \\
\hline Diameter $(\mathrm{mm})$ & $4.836^{\mathrm{a}} \pm 0.09$ & $5.11^{\mathrm{b}} \pm 00.07$ & $5.06^{\mathrm{b}} \pm 0.09$ \\
Thickness (mm) & $0.85^{\mathrm{c}} \pm 0.01$ & $0.79^{\mathrm{a}} \pm 00.01$ & $0.82^{\mathrm{b}} \pm 0.01$ \\
Spread ratio & $5.72^{\mathrm{a}} \pm 0.12$ & $6.38^{\mathrm{c}} \pm 00.12$ & $6.18^{\mathrm{b}} \pm 0.12$ \\
Weight $(\mathrm{g})$ & $7.17^{\mathrm{a}} \pm 0.01$ & $7.26^{\mathrm{c}} \pm 00.01$ & $7.23^{\mathrm{b}} \pm 0.01$ \\
$a^{*}$ & $6.02^{\mathrm{b}} \pm 0.74$ & $5.97^{\mathrm{b}} \pm 00.85$ & $3.88^{\mathrm{a}} \pm 1.55$ \\
$b^{*}$ & $22.69^{\mathrm{b}} \pm 0.73$ & $20.67^{\mathrm{a}} \pm 00.79$ & $25.21^{\mathrm{c}} \pm 0.80$ \\
$L^{*}$ & $68.99^{\mathrm{b}} \pm 0.80$ & $67.6^{\mathrm{a}} \pm 01.14$ & $78.54^{\mathrm{c}} \pm 1.07$ \\
$\Delta E$ & $33.47^{\mathrm{b}} \pm 0.97$ & $33.13^{\mathrm{b}} \pm 01.33$ & $29.61^{\mathrm{a}} \pm 2.04$ \\
Hardness (N) & $23.52^{\mathrm{b}} \pm 0.4 .4$ & $15.04^{\mathrm{a}} \pm 02.54$ & $17.69^{\mathrm{a}} \pm 3.8$ \\
Fracturability (mm) & $39.01^{\mathrm{c}} \pm 0.24$ & $38.52^{\mathrm{a}} \pm 00.31$ & $38.82^{\mathrm{ab}} \pm 0.55$ \\
Appearance & $7.03 \pm 0.69$ & $6.05 \pm 01.00$ & $8.02 \pm 0.72$ \\
Flavor & $7.57 \pm 0.70$ & $5.08 \pm 00.89$ & $7.03 \pm .78$ \\
Hardness at the first bite & $8.12 \pm 0.76$ & $5 \pm 00.84$ & $7.5 \pm 0.68$ \\
Sweetness & $6.4 \pm 1.12$ & $6.08 \pm 01.20$ & $8.12 \pm 0.78$ \\
Overall acceptability & $7.33 \pm 0.68$ & $3.82 \pm 00.79$ & $8.02 \pm 0.70$ \\
Color & $5.67 \pm 0.93$ & $4.07 \pm 00.78$ & $7.05 \pm 0.77$ \\
Mouth feel & $7.18 \pm 0.83$ & $4 \pm 00.84$ & $6.2 \pm 0.84$ \\
\hline
\end{tabular}

$L^{*}$ (lightness), $a^{*}$ (redness) and $b^{*}$ (yellowness). Values are means \pm standard deviation of triplicate. Mean values within a column with the same letter are not significantly different ( $\mathrm{p}>.05)$.

Similar results had been reported by [34] who studied the effect of fat replacement by lentil flour on size of the cookies. The spread factor in MIXFB was found to be the highest 6.38 and incorporation of composite flours reduced this ratio to 5.72 in COMFB. It has been reported that the spreading factor of biscuits prepared from wheat flour decreases with supplantation of buckwheat flour and fenugreek [35]. The spread factor is greatly related to the dough viscosity [36].

\subsection{Colour attributes}

Colour is important in the purchasing and the selection of various food products [37]. Furthermore, as colour develops throughout the last stage of baking, it can be utilized to gauge the completion of the baking procedure [38]. In Table 4 it was observed that the COMFB was significantly darker on the surface when compared to the 
controls. Similar result were reported by [39]. The results of the $L^{*}$ value remained at a lesser level in COMFB and MIXFB when compared to the WF sample. This is unsurprising since lentil is usually seen as a definitely darker colour when compared to wheat flour. $\Delta E$ in COMFB was higher than WFB but no significant variations were between MIXFB and COMFB as showed in the Table 4. Among the factors that contribute to the biscuits, the dark colour was due to maillard reactions between reducing sugar and amino acids [40]. As a result of this nonenzymatic reaction, high-molecular weight macromolecule components referred to as melanoidins were created during baking. Thus, the biscuits colour evolves with increasing baking time and temperature [41], and depends on the amount of sugars and proteins existing in the ingredients utilized for baking [42]. The dark colour of the lentil and wheat bran from WWF will play a significant role in term of biscuit colour.

\subsection{Texture analysis (Three-point break test)}

The effects of the incorporation of lentil and millet flour on texture profile of the biscuits were presented in Table 4. Significant boost $(\mathrm{p} \leq 0.05)$ in the hardness was from addition of lentil and millet flour. Nevertheless, hardness demonstrated a greater value on COMFB $(23.52 \mathrm{~N})$ compared to MIXFB $(15.04 \mathrm{~N})$ and WFB $(17.69 \mathrm{~N})$ respectively. An identical trend was observed in cookies where hardness increased with an increased addition of powder dehydrated Murraya koenigii [43]. The COMFB is demonstrated a higher fracturability (39.012mm) while the MIXFB and WFB showed the $(38.52 \mathrm{~mm})$ and $(38.82 \mathrm{~mm})$ respectively. Similar results have been mentioned the hardness of the high protein and high fiber biscuits by incorporation of sorghum and spirulina flours between $1545.14 \mathrm{~g}$ and $2298.14 \mathrm{~g}$ [44]. In general, cookies made with higher content of protein flour resulted in a harder structure because of the strong binding of starch and protein [45].

\subsection{Scanning electron microscopy}

The biscuits upper surface microstructure is demonstrated in Figure 2. The COMFB displayed many large holes on the upper surface constant with the porous internal structure (Figure 2_a). The top surfaces of WFB have very small pores (Figure 2 e) but there are some big pores on the top surface of MIXFB (Figure 2 c). In the micrographs, the holes and dark colored regions are probably due to addition of LF, MF or WWF. Compared to regular WF biscuit the MIXFB and COMFB had high moisture content $16 \%$ and $15 \%$ respectively and had the largest irregular holes (Figure 2 b,d). The biscuit structure changes are expected to have a significant influence on the materials properties as will become demonstrated in the next subsections [29].
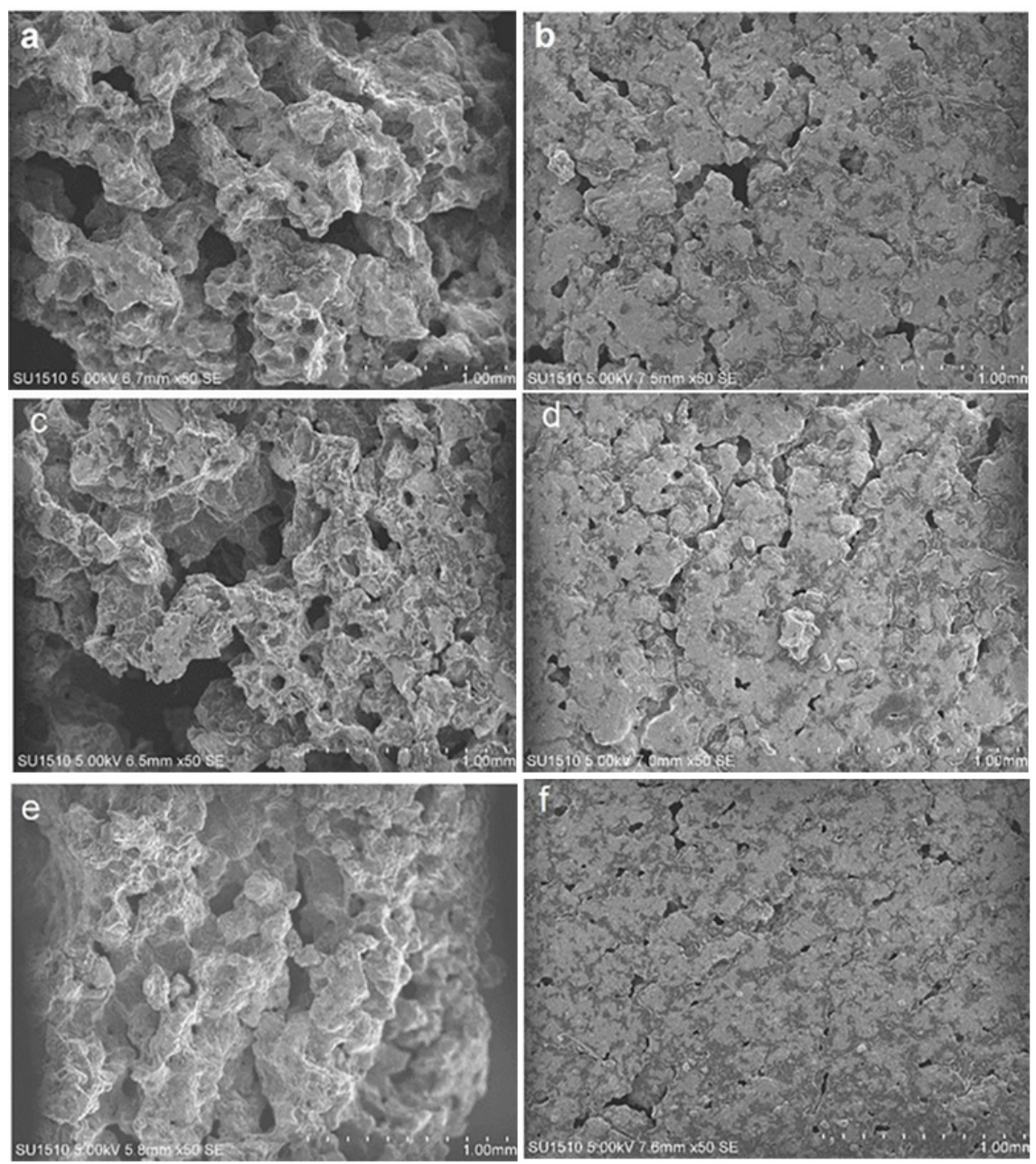

Figure 2. Scanning electron microscopy images (SEM): (a, $c$ and e) were top surface of the COMFB, MIXFB and WFB respectively (b, $d$ and f) were the internal structure of the COMFB, MIXFB and WFB respectively 


\subsection{Sensory Evaluation}

The data related to sensory evaluation was shown in Table 4. The WFB had the highest consumers' acceptance, the consumers disliked the MIXFB, which means the consumers' acceptability of whole wheat flour based products on can be increased by this formula. The COMFB had the hardest texture which had the highest score in term of hardness at the first bite, mouth feel and flavor compare to the controls. Consumers described MIXFB with lowest scores for all parameters were subjected. They disliked MIXFB samples may be due to the strong flavor of WWF bran.

\section{Conclusion}

In this study, the mathematical approach based on Box Behnken Design (BBD) was successfully used to beneficially optimize and develop the Shapporah biscuit formula using composite flour and improved the consumers' acceptability of whole flour biscuits. The colour of the biscuits was noted that the COMFB significantly darkened the surface of biscuits when compared to the MIXFB and WFB. The addition of lentil and millet flour increased the hardness significantly, hardness showed a higher value on COMFB compared to MIXFB and WFB. The biscuits sensory evaluation shows that the COMFB had a higher acceptance than MIXFB, in other words the acceptability of WWF biscuits can be increased by using composite flour such as Yemeni shapporah biscuits formula.

\section{Acknowledgements}

The authors are thankful and grateful to China Scholarship Council and National Natural Science Foundation of China (No. 31471617), and the Fundamental Research Funds for the Central Universities (No. JUSRP51708A) for the financial support. We also thank Mr. Jared wiebelhauus (USA) for language support.

\section{References}

[1] Waleed A., Mahdi A. A., Mohammed J. K., Noman A., and Wang L., "Nutritional Properties of Composite Flour Based on Whole Wheat Flour and Sensory Evaluation of its Biscuits," 2017.

[2] Olaoye O., Onilude A., and Idowu O., "Quality characteristics of bread produced from composite flours of wheat, plantain and soybeans," African Journal of Biotechnology, 5, 11, 2006.

[3] Trichopoulou A., Soukara S., and Vasilopoulou E., "Traditional foods: a science and society perspective," Trends in Food Science \& Technology, 18, 8, 420-27, 2007.

[4] Naska A., Fouskakis D., Oikonomou E., Almeida M., Berg M., Gedrich K., Moreiras O., Nelson M., Trygg K., and Turrini A., "Dietary patterns and their socio-demographic determinants in 10 European countries: data from the DAFNE databank," European Journal of Clinical Nutrition, 60, 2, 181, 2006.

[5] Stewart-Knox B., and Mitchell P., "What separates the winners from the losers in new food product development?," Trends in Food Science \& Technology, 14, 1, 58-64, 2003.

[6] Zhang H., Zhang W., Xu C., and Zhou X., "Morphological features and physicochemical properties of waxy wheat starch," International Journal of Biological Macromolecules, 62, 304-09, 2013.
[7] Ronda F., and Roos Y. H., "Staling of fresh and frozen gluten-free bread," Journal of Cereal Science, 53, 3, 340-46, 2011.

[8] Bhat N. A., Wani I. A., Hamdani A. M., Gani A., and Masoodi F., "Physicochemical properties of whole wheat flour as affected by gamma irradiation," LWT-Food Science and Technology, 71, 175-83, 2016

[9] Turfani V., Narducci V., Durazzo A., Galli V., and Carcea M., "Technological, nutritional and functional properties of wheat bread enriched with lentil or carob flours," $L W T$-Food Science and Technology, 78, 361-66, 2017.

[10] Boye J., Zare F., and Pletch A., "Pulse proteins: Processing, characterization, functional properties and applications in food and feed," Food research international, 43, 2, 414-31, 2010.

[11] Gunenc A., Yeung M. H., Lavergne C., Bertinato J., and Hosseinian F., "Enhancements of antioxidant activity and mineral solubility of germinated wrinkled lentils during fermentation in kefir," Journal of Functional Foods, 32, 72-79, 2017.

[12] Faris M., Takruri H., and AY I., "Role of lentils," Lens culinaris 12349-012, 2012.

[13] Durazzo A., Turfani V., Azzini E., Maiani G., and Carcea M., "Phenols, lignans and antioxidant properties of legume and sweet chestnut flours," Food chemistry, 140, 4, 666-71, 2013.

[14] Johnson C. R., Thavarajah P., Fenlason A., McGee R., Kumar S., and Combs G. F., "A global survey of low-molecular weight carbohydrates in lentils," Journal of Food Composition and Analysis, 44, 178-85, 2015.

[15] Rathi A., Kawatra A., Sehgal S., and Housewright B., "Influence of depigmentation of pearl millet (Pennisetum gluacum L.) on sensory attributes, nutrient composition and in vitro digestibility of biscuits," LWT-Food Science and Technology, 37, 2, 187-92, 2004

[16] Abdalla A., El Tinay A., Mohamed B., and Abdalla A., "Proximate composition, starch, phytate and mineral contents of 10 pearl millet genotypes," Food chemistry, 63, 2, 243-46, 1998.

[17] Sudha M., Vetrimani R., and Leelavathi K., "Influence of fibre from different cereals on the rheological characteristics of wheat flour dough and on biscuit quality," Food chemistry, 100, 4, 1365-70, 2007.

[18] Potty V., "Physio-chemical [physico-chemical] aspects, physiological functions, nutritional importance and technological significance of dietary fibres: A critical appraisial," Journal of Food Science and Technology, 33, 1, 1-18, 1996.

[19] Nazni P., and Gracia J., "Optimization of Fibre Rich Barnyard Millet Bran Cookies Using Response Surface Methodology," International Journal of Agriculture and Food Science, 4, 100-05, 2014.

[20] Gunst R. F., "Response surface methodology: process and product optimization using designed experiments," Taylor \& Francis Group, 1996.

[21] Danbaba N., Nkama I., and Badau M. H., "Application of response surface methodology (RSM) and central composite design (CCD) to optimize minerals composition of rice-cowpea composite blends during extrusion cooking," International Journal of Food Science and Nutrition Engineering, 5, 1, 40-52, 2015.

[22] Dahmoune F., Boulekbache L., Moussi K., Aoun O., Spigno G., and Madani K., "Valorization of Citrus limon residues for the recovery of antioxidants: evaluation and optimization of microwave and ultrasound application to solvent extraction," Industrial Crops and Products, 50, 77-87, 2013.

[23] Bezerra M. A., Santelli R. E., Oliveira E. P., Villar L. S., and Escaleira L. A., "Response surface methodology (RSM) as a tool for optimization in analytical chemistry," Talanta, 76, 5, 965-77, 2008.

[24] Protonotariou S., Batzaki C., Yanniotis S., and Mandala I., "Effect of jet milled whole wheat flour in biscuits properties," LWT-Food Science and Technology, 74, 106-13, 2016.

[25] Noor Aziah A., Mohamad Noor A., and Ho L.-H., "Physicochemical and organoleptic properties of cookies incorporated with legume flour," 2012.

[26] Kaur M., Sandhu K. S., Arora A., and Sharma A., "Gluten free biscuits prepared from buckwheat flour by incorporation of various gums: physicochemical and sensory properties," LWT-Food Science and Technology, 62, 1, 628-32, 2015.

[27] Mesías M., Holgado F., Márquez-Ruiz G., and Morales F. J., "Risk/benefit considerations of a new formulation of wheat-based biscuit supplemented with different amounts of chia flour," LWT-Food Science and Technology, 73, 528-35, 2016. 
[28] Zouari R., Besbes S., Ellouze-Chaabouni S., and Ghribi-Aydi D., "Cookies from composite wheat-sesame peels flours: Dough quality and effect of Bacillus subtilis SPB1 biosurfactant addition," Food chemistry, 194, 758-69, 2016.

[29] Saleem Q., Wildman R., Huntley J., and Whitworth M., "Material properties of semi-sweet biscuits for finite element modelling of biscuit cracking," Journal of food engineering, 68, 1, 19-32, 2005.

[30] Chu C., and Resurreccion A., "Optimization of a chocolate peanut spread using response surface methodology (RSM)," Journal of sensory studies, 19, 3, 237-60, 2004.

[31] Błońska A., Marzec A., and Błaszczyk A., "Instrumental Evaluation of Acoustic and Mechanical Texture Properties of Short-Dough Biscuits with Different Content of Fat and Inulin," Journal of texture studies, 45, 3, 226-34, 2014.

[32] Getachew A. T., and Chun B.-S., "Optimization of coffee oil flavor encapsulation using response surface methodology," $L W T$ Food Science and Technology, 70, 126-34, 2016.

[33] Ryan K., and Brewer M., " PHYSICAL PROPERTIES OF SUGAR-SNAP COOKIES USING GRANULE SURFACE DEPROTEINATED WHEAT STARCH," Journal of texture studies, 37, 4, 442-57, 2006.

[34] Ashraf S., Ghufran SaeedS M., Sayeed S. A., Kanwar H., Ahmed M., and Ali R., "Impact of Lentil Fortification on Physical, Chemical and Instrumental Properties of Dough and its Influence on overall Quality of Cookies," Arab Gulf J. Sci. Res, 30, 125-34, 2012.

[35] Hooda S., and Jood S., "Organoleptic and nutritional evaluation of wheat biscuits supplemented with untreated and treated fenugreek flour," Food chemistry, 90, 3, 427-35, 2005.

[36] Pareyt B., and Delcour J. A., "The role of wheat flour constituents, sugar, and fat in low moisture cereal based products: a review on sugar-snap cookies," Critical reviews in food science and nutrition, 48, 9, 824-39, 2008.
[37] Calvo C., Salvador A., and Fiszman S. M., "Influence of colour intensity on the perception of colour and sweetness in various fruit-flavoured yoghurts," European Food Research and Technology, 213, 2, 99-103, 2001.

[38] Wade P., Biscuits, cookies, and crackers: Elsevier applied science, 1988.

[39] Krishnan R., Dharmaraj U., Manohar R. S., and Malleshi N., "Quality characteristics of biscuits prepared from finger millet seed coat based composite flour," Food chemistry, 129, 2, 499-506, 2011.

[40] Morales F. J., and Jimenez-Perez S., "Free radical scavenging capacity of Maillard reaction products as related to colour and fluorescence," Food chemistry, 72, 1, 119-25, 2001.

[41] Köksel H., and Gökmen V., "Chemical reactions in the processing of soft wheat products," Food Engineering Aspects of Baking Sweet Goods37-38, 2008.

[42] Mesias M., Holgado F., Marquezruiz G., and Morales F. J., "Risk/benefit considerations of a new formulation of wheat-based biscuit supplemented with different amounts of chia flour," Lwt Food Science and Technology, 73, 528-35, 2016.

[43] Drisya C., Swetha B., Velu V., Indrani D., and Singh R., "Effect of dried Murraya koenigii leaves on nutritional, textural and organoleptic characeteristics of cookies," Journal of food science and technology, 52, 1, 500-06, 2015.

[44] Singh P., Singh R., Jha A., Rasane P., and Gautam A. K., "Optimization of a process for high fibre and high protein biscuit," Journal of food science and technology, 52, 3, 1394-403, 2015.

[45] Park J., Choi I., and Kim Y., "Cookies formulated from fresh okara using starch, soy flour and hydroxypropyl methylcellulose have high quality and nutritional value," LWT-Food Science and Technology, 63, 1, 660-66, 2015. 